\title{
CONSPIRAÇÃO AQUARIANA REVISITADA: CORRELAÇÕES COM AS FILOSOFIAS DE HENRI BERGSON E WILLIAM JAMES
}

\author{
The Aquarian Conspiracy Revisited: Correlations with the Philosophies of Henri Bergson \\ and William James \\ Conspiración Acuariana Renovada: Correlaciones con las Filosofías de Henri Bergson \\ e William James
}

Azize Maria Yared de MedeIRos

\begin{abstract}
Resumo: Trata-se de um exercício de reflexão sobre o livro “Conspiração Aquariana”, de Marilyn Ferguson, que marca o início de uma "nova era" nas sociedades ocidentais, quando críticas ao paradigma racionalista das ciências apontam o surgimento de uma "revolução da consciência". Após caracterizar as sociedades pós-modernas, com suas crises epistemológicas e de sentido, reforça-se a atualidade do texto de Ferguson, que indica o renascer de uma nova espiritualidade em busca de experiências místicas, salientando que o verdadeiro conhecimento é de ordem interna. Estabelecemos uma relação com a filosofia para mostrarmos a contemporaneidade e importância das afirmações de Ferguson - algumas claramente reconhecidas nos estudos de Bergson e James: a intuição como forma de conhecimento que supera a insatisfação com os limites da racionalidade e a conduz à essência daquilo que está sendo conhecido; a fé como resultante da vontade de confirmar o que antecipadamente sabemos ser real. Concluímos apresentando a emergência da "conspiração", em seu sentido literal, como parte essencial da espiritualidade capaz de sustentar a vida no planeta.
\end{abstract}

Palavras-chave: Conspiração; Intuição; Racionalidade; Experiência mística.

Abstract: Analysis of the book The Aquarian Conspiracy by Marilyn Ferguson, which focuses on the origins of a "New Age" within western societies. Ferguson reviews aspects of the social movements that questioned the rational scientific paradigm leading to the birth of a "consciousness revolution". After describing the confusion and crisis of belief and knowledge that occurs in post-modern societies, it is shown that Ferguson's arguments points out that a rebirth of a new spirituality (based in the search for mystical experiences) is motivated by the idea that true knowledge comes from within the individual. There is a strong correlation between Ferguson's assertion and the philosophical studies of Bergson and James in two primary ways: Intuition as a form of knowledge overcomes the limits of rationality and leads to the essence of what is being known, and faith is the result of the will to confirm what we have already anticipated as being real. Our conclusion presents the emergence of a real conspiracy as the foundation of a global spirituality capable of sustaining life on this planet promoted and supported by individuals.

Keywords: Conspiracy; Intuition, Rationality; Mystical experiences.

Resumen: Se trata de un ejercicio de reflexión sobre el libro “Conspiración Acuariana”, de Marilyn Ferguson (1980), que marca el inicio de una "nueva era" en las sociedades occidentales, cuando las críticas al paradigma racionalista de las ciencias apuntan al surgimiento de una "revolución de la consciencia". Después de caracterizar las sociedades pos-modernas, con sus crisis epistemológicas y de significado, se refuerza la actualidad del texto de Ferguson, que indica el renacimiento de una nueva espiritualidad en la búsqueda de experiencias místicas, destacando que el verdadero conocimiento es de orden interno. Establecemos una relación con la filosofía para mostrar la contemporaneidad y la importancia de las afirmaciones de Ferguson - algunas claramente reconocidas en los estudios de Bergson y James: La intuición como forma de conocimiento que supera la insatisfacción con los límites de la racionalidad y la conduce a la esencia de aquello que esta siendo conocido; la fe como resultado de la voluntad de confirmar lo que anticipadamente sabemos como real. Concluimos presentando la emergencia de la "conspiración", en su sentido literal, como parte esencial de la espiritualidad capaz de sostener la vida en el planeta.

Palabras-clave: conspiración; intuición, racionalidad; experiencia mística

\section{Introdução}

No início dos anos 80 do século XX, a jornalista americana Marilyn Ferguson lançou o livro "Conspiração Aquariana” (1980). Nesse livro apontava os sinais evidentes da crise que se instalava nas sociedades ocidentais, mais particularmente nos Estados Unidos, resultantes de um modelo de desenvolvimento que se tornara excessivamente racionalista e cientificamente arrogante. Parecia evidente, pelos dados das muitas pesquisas mencionadas por Ferguson, que surgia nas mais diversas áreas do conhecimento certa reação de desconforto e oposição aos excessos materialistas das sociedades de consumo, que parecia transformar-se em uma "revolução silenciosa", 
manifestando-se contra as limitações impostas por tal modelo de desenvolvimento. Iniciava-se um sério questionamento sobre os paradigmas utilizados pela ciência, a falácia desses paradigmas e os limites de seus métodos reducionistas, adequados, talvez, apenas às ciências naturais, cuja lógica não poderia ser estendida aos demais campos do conhecimento. Tal discussão tornou-se mais acirrada desde a publicação, nos anos 1960, das análises de Thomas Kuhn sobre o conceito de revolução científica (Kuhn, 2001). Começaram a surgir e se estabelecer grupos imbuídos de um profundo senso humanístico propondo novas e diferenciadas abordagens nas áreas de educação, saúde, política e administração. Esses grupos, alguns dos quais seriam mais tarde chamados de New Age, buscavam integrar ciência e magia ou, utilizando uma linguagem weberiana, estavam comprometidos em "reencantar" o mundo. Tais grupos mostravam-se cansados das explicações racionais a respeito do mundo, bem como do descaso com que eram tratadas as muitas dimensões da experiência humana.

Tornara-se evidente que a visão de mundo newtoniana-cartesiana não apresentava soluções para os problemas de uma modernidade em transição. O dualismo já cristalizado no pensamento do ocidente comprometia os esforços para um melhor entendimento dos processos de transformação social e impedia uma visão de totalidade do mundo. As teorias filosóficas, ainda visceralmente aristotélico-tomistas e comteanas, fundamentadas em parâmetros empiristas e racionalistas, insistiam em proclamar a existência de certezas e verdades absolutas que, infelizmente, não ofereciam respostas para a crise que se instalava nas sociedades ocidentais, cujas características sinalizavam o surgimento de algo absolutamente novo na história da humanidade, algo que seria chamado por alguns de pós-modernidade ou modernidade tardia.

Hoje, quase trinta anos após o lançamento do livro de Ferguson, constata-se a culminância de uma nova forma de capitalismo, não mais representada por estados-nações, mas, sim, por grandes conglomerados de empresas que ultrapassam qualquer tipo de fronteira, caracterizando definitivamente aspectos da sociedade que vieram a ser denominados de "globalização", fato resultante não só da expansão dos sistemas de comunicação, promovida pelo lançamento do primeiro satélite na atmosfera, mas também complementada pelo desenvolvimento acelerado da internet, com seus computadores domésticos.

O materialismo dessas sociedades capitalistas engajadas em um consumismo voraz, fator determinante para o acúmulo de bens, na maioria das vezes supérfluos, veio acrescentar às vidas humanas riscos diferentes dos já naturalmente conhecidos. Exatamente o que Giddens (2006, p. 36) chama de "risco fabricado, aquele (...) criado pelo próprio impacto de nosso crescente conhecimento sobre o mundo".

É possível afirmar que o aquecimento global (a grande preocupação dos dias atuais) e suas conseqüências resul- tam diretamente da ganância, do lucro e da falta de uma consciência cósmica planetária. Os ambientalistas são unânimes em declarar que as alterações climáticas que atingem todos os povos da terra provocam situações difíceis e, na maioria das vezes, impossíveis de serem evitadas ou controladas pela ciência. A globalização, com seu livre comércio, vem provocando a destruição ambiental numa escala planetária. Já é consenso que a própria cadeia alimentar, que mantém a sobrevivência da espécie humana, encontra-se perigosamente comprometida. Em nome do lucro, organismos geneticamente modificados - como os transgênicos - estão sendo acrescentados à alimentação humana sem uma correta e permanente avaliação dos riscos ao meio ambiente e à vida. Com a equivocada justificativa de que somente a biotecnologia vai resolver a fome das gerações futuras, empresas multinacionais lançam no mercado produtos que atendem somente a interesses comerciais, provocando riscos à saúde, destruindo ecossistemas e levando à miséria os agricultores locais.

A ciência, portanto, está se tornando refém das grandes empresas. Isso sem também mencionar os constantes riscos de catástrofes nucleares e a problemática dos lixos industriais, tóxicos e atômicos, lixos esses, aliás, que continuam sendo exportados para os países mais pobres.

Os países desenvolvidos oferecem preços lucrativos (em termos terceiro-mundistas) a empresas de 'reciclagem' do Terceiro Mundo para aceitarem seu material para 'processamento'[...] o custo de tratar e descartar o lixo de maneira sustentável no Norte ficou altíssimo [...] Países ricos como Austrália e EUA continuam a exportar lixo [...] Hoje a Ásia continua a ser o maior depósito de lixo para os resíduos do Ocidente (Shiva, citado por Giddens \& Hutton, 2004, pp. 168-169).

Vive-se hoje também um permanente processo de destradicionalização. As migrações, o ir-e-vir constante de povos e etnias, o confronto e a inter-relação de culturas, proporcionados pelo desmoronar de fronteiras, de estados e de sistemas políticos, pelo surgimento de novas nações, bem como pelas catástrofes ambientais, provocaram na sociedade global um novo sentido de liberdade e individualidade. Perderam-se as referências tradicionais. As sociedades contemporâneas produziram grandes transformações na vida do ser humano. São sociedades onde é necessário, de acordo com Corbí (1996), viver a inovação, a criação contínua de conhecimento, informação e tecnologia. Essas sociedades mantêm um vínculo indissociável (e nem sempre defensável) da idéia de progresso.

Torna-se bastante evidente, por conseguinte, que

A moderna sociedade capitalista legou à humanidade, portanto, um mundo destituído de sentido. A confiança depositada na ciência sofreu abalos irreversíveis. O campo científico desenvolveu-se atrelado à idéia de progresso. E esse progresso trouxe, embutido em seus aparentes ganhos, conseqüências de risco para a humanidade, (...) que 
ultrapassam a própria capacidade científica de encontrar soluções ou de criar estratégias que possam remediá-los ou minimizá-los (Medeiros, 2007, p. 43).

A crise que se manifesta na pós-modernidade é, conseqüentemente, de ordem epistemológica. Os fundamentos nos quais foram embasadas as teorias do conhecimento "se revelaram sem credibilidade", como afirma Giddens (1991, p. 52).

É possível assegurar que não se trata apenas de uma crise social e econômica, mas também axiológica. O pluralismo cultural mostra que não existem mais valores comuns. As sociedades pós-modernas não herdaram um sistema de valores pleno de sentido das tradições. Não há mais possibilidade de buscar referência em modelos tradicionais, porque nunca houve na história um momento como este. As decisões que anteriormente eram asseguradas pela comunidade ou por meio do conhecimento de seus ancestrais hoje perderam todo o significado. É impossível recorrer ao passado em busca de respostas.

O sentido ontológico parece ter-se esvaído ou modificado na efervescência cultural das sociedades contemporâneas. "As sociedades atuais nos oferecem uma intrigante perda de identidade, identidade aqui entendida como algo uno, inteiro e estável, tanto do ponto de vista individual quanto comunitário” (Medeiros, 2007, p. 46). Nesse caldeirão de elementos tão plurais, tão híbridos, buscam-se novos modos de atribuir significado à vida.

A procura da identidade se faz hoje por meio da experiência subjetiva, na construção autônoma e individualizada da própria vida. A valorização da experiência pessoal, da subjetividade, também ocorre de forma relacional, porém diferenciada. O ser humano pós-moderno não abre mão de viver coletivamente sua individualidade. Mas a busca de sentido torna-se algo privado, transforma-se em autoconhecimento, aquilo que deve ser vivido interiormente e compartilhado apenas entre seus iguais.

O desejo mais generalizado do mundo ocidental, como diz Beck (citado por Giddens \& Hutton, 2004, p. 235), é levar “a própria vida (...) a luta diária pela própria vida tornou-se a experiência coletiva do mundo ocidental. Exprime o que resta de nosso sentimento comunitário".

Durante muitos séculos, no pensamento ocidental, a ciência foi utilizada para confirmar a fé. Embora a separação da ciência e religião tenha sido necessária para o melhor desenvolvimento do conhecimento humano, criou-se o dualismo psicofísico, uma fragmentação que tornou a humanidade desesperançosa e insatisfeita. O homem se viu dividido entre aquilo que desejava acreditar, fruto de sua intuição e reflexão, e aquilo que lhe apresentavam como sendo possível de ser acreditado, por ser "científico" e verdadeiro. Embora o aspecto religioso tenha sido relegado ao campo da crença particular, as metafísicas racionalistas e o comprometimento das instituições religiosas com o poder instituído aprofundaram o processo de secularização, que já vinha se manifestando desde o início da industrialização. Conforme Berger e Luckmann (2004, p. 48), no entanto, “A ‘desigrejização’ não deve ser confundida com perda de religiosidade". O individualismo pós-moderno proporcionou ao ser humano a busca interior - a ampliação de sua própria consciência em contato com o mysterium.

Reportando-nos mais especificamente à realidade brasileira, essa busca de sentido manifesta-se de duas formas, de acordo com Sérgio da Mata (Mata, 2007, p. 43): “(...) entre as camadas sociais médias e elevadas, individualização; junto aos estratos inferiores das camadas médias e aos mais pobres, efervescência religiosa e eclesiogênese". Essa última pode ser observada no surgimento crescente de novas igrejas.

Percebe-se, que o racionalismo, tão precioso para os iluministas e responsável pelo surgimento das sociedades altamente tecnológicas e informatizadas, procurou afastar os elementos míticos das metafísicas modernas, promovendo a secularização e a expulsão de qualquer forma de magia, tanto na religião quanto na ciência. Mas, historicamente, sabemos que o próprio período das luzes não conseguiu apagar algumas vozes discordantes: dos representantes do romantismo, dentre eles Rousseau, que alertavam para os perigos daquilo que já antecipavam como sendo "os males da civilização" - o universalismo. A globalização tem se empenhado em tornar as pessoas todas iguais, consumidoras dos mesmos produtos e donas das mesmas atitudes - perigosamente homogêneas.

Assim, o romantismo representa uma reação contrária à insistência em uniformizar a vida; um modo de denunciar o homogeneizante esvaziamento da complexidade do humano; uma forma de impedir que seja descartado o esforço intrínseco do humano em busca da sua totalidade ontológica - algo que não pode ser submetido às leis da física e das

lógicas racionalista e empirista (Medeiros, 2007, p. 55).

Para Duarte (2003, p. 16), a pós-modernidade retomou os princípios românticos do pensamento ocidental, ou seja, "(...) uma crítica do universalismo em nome da singularidade, da intensidade e da experiência”.

\section{Revisitando a Conspiração Aquariana}

Em consonância com essas idéias, encontramos em Eliade a afirmação de que "um homem inteiramente racional é uma abstração" (Eliade, 1992, p. 170). Afirma que o ser humano é constituído, ao mesmo tempo, de uma atividade consciente e de experiências irracionais. Segundo esse autor, o homem é movido por pulsões que chegam do mais profundo do seu ser, e os conteúdos e estruturas do inconsciente manifestam-se em forma de símbolos e mitos. Para o autor o ser humano vive uma "inextinguível sede ontológica: é sedento de Ser”. 
Toda essa busca vem permeando o desenvolvimento epistemológico do ocidente. Quando Ferguson apresenta as pesquisas recentes, na época, sobre o cérebro e a mente, que parecem contradizer a lógica clássica, está simplesmente alertando para o fato de que existem outras formas de conhecimento, diferentes do paradigma até então utilizado pela ciência racional, que abrem novos horizontes, mostrando as possibilidades do encontro de sentido no conhecimento interior, uma significância além de qualquer tipo de questionamento.

A experiência mística ou espiritual (...) é a imagem no espelho da ciência - uma percepção direta da unidade da natureza, o interior do mistério que a ciência tenta bravamente conhecer de fora... Essa forma de entendimento antecede a ciência de milênios. Muito antes que a humanidade dispusesse de instrumentos como a lógica quântica para descrever os fatos que a razão comum não consegue entender, os indivíduos penetravam no domínio do paradoxo através de uma mudança de consciência. E lá, eles sabem que o que não pode ser é. Milhões de pessoas que vivem hoje experimentam aspectos transcendentes da realidade e incorporam tais conhecimentos a suas vidas (Ferguson, 1980, p. 372).

A experiência mística é o encontro com a consciência cósmica, algo que transcende essa realidade fragmentada e conduz à real dimensão do todo, pleno de significado. Esse é o objetivo primeiro do caminho espiritual e a grande meta do ser humano. Uma forma de atribuir sentido à vida, que já havia sido prevista por Troeltsch em 1913 (Mata, 2007), quando afirmava que o afastamento das igrejas e a volta do subjetivismo significavam que o ser humano ocidental estava buscando outros caminhos para viver a sua espiritualidade: “(...) é provável”, afirmava ele, "que ainda possa haver outros estilos de vida religiosa” (Mata, 2007, p. 8).

William James, no final do século XIX e começo do século XX, ampliou seus estudos sobre a psique humana, rejeitando os excessos do racionalismo e integrando ao seu pensamento a dimensão espiritual, considerando assim as experiências místicas como fonte de conhecimento. Diferentemente da visão mecanicista e comportamentalista da época, James não reduzia a consciência a fenômenos cerebrais. Para ele o aspecto espiritual representava o centro do Eu.

Na experiência mística, a pessoa poderia se identificar com seu Eu real e tomar consciência dessa parte superior em si mesma, o que, mais tarde, viria a ser denominado, por Jung, de Self. James se interessava em estudar exatamente a experiência individual direta com o divino: o ser humano em seu contato com o mysterium tremendum e fascinans. Ele criticava o pensamento racionalista ao afirmar que essa abordagem se limitava apenas aos aspectos sensoriais e visíveis da realidade. Já as experiências da consciência profunda eram inalcançáveis por esse tipo de abordagem, podendo ser vividas pelas pessoas. Enfatizava a importância de a experiência subjetiva jamais ser omitida como fonte de conhecimento. James chega a afirmar, a partir de dados de suas próprias pesquisas, que a vida espiritual pode provocar efeitos psicológicos e materiais no mundo fenomênico.

Os estudos de James encontraram eco nas reflexões e análises do filósofo francês Henri Bergson, o que os levou a uma profícua troca de correspondência. Esse último se opunha de forma enfática ao que ele chamava de "pensamento tradicional": a reflexão construída de Platão até o século XVII e que, a partir da modernidade, passa a ser norteada pelo método de Descartes. A obra de Bergson mostra que um dos problemas da modernidade se encontra no fato de a ciência do séc.XIX ter aceitado, sem críticas, toda a herança metafísica do séc.XVII. Tal constatação deu origem ao principal objetivo da filosofia de Bergson - exatamente a superação do dualismo.

Bergson (1978) apresenta o conceito de intuição como um dos principais fundamentos de sua reflexão filosófica. Esse filósofo considerava a experiência mística como fonte inquestionável de conhecimento. Para ele, a intuição mística leva os homens à plenitude do ser, pois essa intuição é a participação humana na essência divina.

Bergson estabelece uma diferença entre a inteligência, faculdade racional que nos permite captar a realidade estática e fragmentária, e a intuição, instrumento adequado à metafísica, já que consegue captar a duração, o movimento, o permanente vir-a-ser de todos os seres e, portanto, do próprio universo. Para o filósofo, inteligência e intuição são instrumentos gnoseológicos complementares. Bergson encontrou nos seus estudos de experiências místicas, tanto orientais quanto ocidentais, a possibilidade de fundamentar uma teoria do conhecimento baseada na intuição. Cita como exemplo os grandes místicos cristãos, como São Paulo, Santa Teresa, São Francisco, Joana D’arc e outros, que ele chamaria de místicos de ação. Ele afasta da sua área de estudo os chamados místicos contemplativos. Seu interesse pela religião é de cunho filosófico e não teológico. É fruto do seu interesse pela ação, pois para ele a religião não é teoria, mas prática. O importante para esse filósofo é a transformação da alma proporcionada pela experiência mística (algo que na pós-modernidade aquariana será chamado de "experiências do sagrado").

Para Bergson, o misticismo é parte do gênio humano. A inteligência, como instrumento da razão e da lógica clássicas, levou os seres humanos à desesperança. Para ele o misticismo se encontra no que chama de religião aberta, a religião dinâmica, a religião do amor. Isso, em oposição à religião fechada, uma religião estática - aquela que impede as arbitrariedades e se mantém como fator de coesão social. A participação na religião aberta exige um esforço que só pode ser individual e espiritual. Permite que a alma reencontre a confiança e realize sua ligação com a vida - "a sua inseparabilidade deste princípio, alegria na alegria, amor, daquilo que somente é amor” (VieillardBaron, 2007, p. 53). 
Dois grandes nomes da filosofia ocidental, James e Bergson, no início do século XX, já questionavam a força do positivismo no campo das ciências e alertavam para a necessidade de aceitação de um tipo de conhecimento humano, não necessariamente lógico e racional, de acordo com os parâmetros estabelecidos na época, mas baseado na experiência subjetiva.

Retornando a Ferguson (1980), observamos que ela definia aquele momento - que vinha amadurecendo desde os anos 60 - como sendo a síntese de uma "revolução da consciência", que se encaminhava para a transformação da sociedade resultante de uma transformação pessoal, ou seja, uma mudança de dentro para fora. Possibilidade essa já preconizada por James e Bergson. Ela mostrava e descrevia de maneira extensa, muitos exemplos dessa transformação, que não só já estava ocorrendo, como havia sido anteriormente prevista e anunciada por muitos filósofos, psicólogos, cientistas, escritores e artistas em geral.

A busca de sentido ontológico por meio de experiências subjetivas passou a se desenvolver de forma mais acentuada nas sociedades ocidentais pós-modernas, não só a partir do conhecimento trazido pelos orientais ${ }^{1}$ no campo da meditação, como também as muitas experiências com drogas psicoativas, o xamanismo e o retorno ao misticismo cristão.

As questões ecológicas promoveram um retorno aos ritos primitivos de encontro com a Mãe Natureza. A própria idéia da terra como um organismo vivo (a teoria de Gaia, de James Lovelock) é um dos sustentáculos da teoria Ecologia Profunda, desenvolvida por Arne Naess (citado por Terrin, 2004), a qual representa o braço ambientalista da conspiração a que Ferguson se refere. Uma das características mais marcantes dessa conspiração manifesta-se no retorno e culto à natureza. Na busca de respostas para evitar a acelerada destruição da fauna e da flora no mundo todo, as pessoas passaram a se relacionar de forma mística com a natureza, como parte de um todo comum, de origem cósmica. A Ecologia Profunda tem como principal característica exatamente o desenvolvimento da consciência de que os seres humanos são parte de uma unidade indissolúvel. Os ambientes, os organismos e as pessoas não são entes separados. Todos fazem parte de uma mesma teia onde uns dependem dos outros para existir e coabitar neste planeta. Isso implica não só o conhecimento dessa realidade, mas principalmente o respeito e a compreensão de que a existência da teia é mantida pela ligação espiritual de todas as realidades envolvidas. Isso não coloca os seres humanos num plano hierárquico superior a uma formiga ou a um golfinho. Todos têm exatamente o mesmo nível de importância para a existência e a continuidade harmônica e equilibrada da teia. Ou seja, cada um depende de todos os outros. Terrin (2004, p. 131), citando Naess, salienta que toda realidade está em relação

\footnotetext{
1 Para as grandes tradições orientais, como o taoísmo, o budismo e o hinduísmo, a não-separação e a interdependência de todas as realidades viventes fundamentam sua filosofia e religiosidade.
}

de interdependência com a concepção humana do mundo. Daí a necessidade de o ser humano elaborar um verdadeiro modelo sistêmico em que haja a compreensão de que "cada coisa depende de todas as outras".

Portanto, acrescenta ele, "só com uma mente unificada e um pensamento não fragmentado é possível ter respeito pelo mundo e por toda a realidade" (Terrin, 2004, p. 132). Essa maneira de ver o mundo aponta a necessidade urgente de refletir sobre relações de poder estruturadas a partir de crenças antropocêntricas.

O que poderia parecer apenas um alerta acadêmico de filósofos, cientistas e artistas no sentido de repensar toda a base epistemológica utilizada na construção do mundo ocidental, é parte intrínseca daquilo que Ferguson chamava "conspiração".

Parece que hoje, em plena globalização, é necessário apontar para a urgência de vivenciar o sentido literal da palavra conspiração: respirar juntos para, assim, assegurar a sustentabilidade da vida no planeta. Aquilo que Teilhard Chardin denominava "conspiração do amor" nada mais é do que a "Conspiração Aquariana" dos anos 1980.

Observa-se, portanto, a atualidade do desafio lançado pela própria Ferguson no último capítulo de seu livro:

Ricos como somos - juntos - podemos fazer qualquer coisa. Temos a capacidade de fazer a paz dentro de nossos próprios e esfrangalhados eus e entre nós, de purificar nossa terra natal, a Terra Toda. Olhamos para todas as razões que temos para dizer Não: os esquemas sociais falidos, os tratados descumpridos, as chances perdidas. E apesar disso ainda existe o Sim, a mesma busca obstinada que nos levou das cavernas à Lua em um átimo do tempo cósmico. Uma nova geração está crescendo dentro de um paradigma mais amplo; assim tem sido sempre. Em muitos contos de ficção científica, aos adultos é impedida a transformação experimentada por uma nova geração. Seus filhos se desenvolvem inexoravelmente além deles, para uma realidade maior. Aqueles de nós nascidos dentro do paradigma da "Terra dividida" têm duas escolhas: podemos ser enterrados com nossas velhas convicções, como as gerações de cientistas tradicionalistas que insistiam que não existiam coisas tais como meteoritos, germes, ondas cerebrais, vitaminas - ou, podemos relegar ao passado, sem sentimentalismo, nossas velhas convicções, adotando a perspectiva mais real e mais forte. Podemos ser nossos próprios filhos (Ferguson, 1980, pp. 415-416).

Tais afirmações de Ferguson remetem às frases finais do último livro escrito por Bergson, que versa sobre moral e religião, de 1932, quando ele se encontrava desolado com a desastrosa primeira grande guerra e, ao mesmo tempo, já alertava para o possível surgimento de um outro conflito mundial de maiores proporções. $\mathrm{O}$ autor diz que "a humanidade geme, meio esmagada sob o progresso que conseguiu" e essa humanidade, afirma ainda, "não sabe o suficiente que seu futuro depende dela", tendo, portanto que "decidir primeiro se quer continuar a viver" (Bergson, 1978, p. 262). 


\section{Considerações Finais}

Hoje, atravessando a primeira década do terceiro milênio, a humanidade vive exatamente o momento dessa inadiável decisão. Trata-se realmente - e aqui residem não só as constatações místicas, mas certamente, do mesmo modo, as científicas - de decidir se a vida humana terá continuidade neste planeta.

Ao considerar as análises citadas neste artigo, conclui-se que tais decisões não dependem exclusivamente da inteligência e racionalidade, mas também das fontes de conhecimento não verificáveis experimentalmente, porém resultantes de profundas experiências de introspecção e expansão da consciência. Em outras palavras: permitir que as ações sejam determinadas pelo trabalho conjunto de intuição e inteligência - uma forma de superar o imenso hiato criado ao longo dos séculos entre esses dois componentes complementares e organizadores do conhecimento humano.

\section{Referências Bibliográficas}

Berger P. L. \& Luckmann, T. (2004). Modernidade, pluralismo e crise de sentido: a orientação do homem moderno. Petrópolis: Vozes.

Bergson, H. (1978). As duas fontes da moral e da religião. Rio de Janeiro: Zahar.

Corbí, M. (1996). Religion sin religion. Madrid: PPC Editorial.

Duarte, L.F.D. (2003). A pulsão romântica e as ciências humanas no ocidente. Revista Brasileira de Ciências Sociais, 19, (55), 5-19.

Eliade, M. (1992). O sagrado e o profano - a essência das religiões. São Paulo: Martins Fontes.

Ferguson, M. (1980). A conspiração aquariana. Rio de Janeiro: Record.

Giddens, A. \& Hutton, W. (2004) (Orgs.). No limite da racionalidade. Rio de Janeiro: Record.

Giddens, A. (1991) As conseqüências da modernidade. São Paulo: UNESP.

Giddens, A. (2006). Mundo em descontrole. Rio de Janeiro: Record.

James, W. (2004). The varieties of religious experience - a study in human nature. New York: Barnes \& Noble Classics.

Kuhn, T. S. (2001). A estrutura das revoluções científicas. São Paulo: Perspectiva.

Mata, S. (2007). Religião e modernidade em Ernst Troeltsch. Artigo apresentado por ocasião da aula inaugural do Mestrado em Ciências da Religião, da Universidade Católica de Goiás, em 2007. Manuscrito inédito.
Medeiros, A. (2007). Peregrinos pós-modernos: a permanente busca do sagrado no universo da nova era. Dissertação de Mestrado em Ciências da Religião, Universidade Católica de Goiás, Goiânia.

Terrin, A. (2004). Antropologia e horizontes do sagrado - culturas e religiões. São Paulo: Paulus.

Vieillard-Baron, J-L. (2007). Compreender Bergson. Petrópolis: Vozes.

Azize Maria Yared de Medeiros - Possui graduação em Filosofia pela Universidade Federal do Paraná, e Mestrado em Ciências da Religião pela Universidade Católica de Goiás (UCG). Endereço para correspondência: Rua S 4 n. 247, Ap. 504, Setor Bela Vista, Goiânia - GO, CEP 74823-450. E-mail: <azizemedeiros21@yahoo.com.br>

Recebido em 09.05.08 Primeira Decisão Editorial em 13.08.08 Aceito em 12.09.09 